\title{
Association between Leukemia and Exon 2 CD19 Gene Variants in a sample of Iraqi Patients
}

\author{
Najwa Sh. Ahmed,* \\ Zeina S. M. Al-Hadeithi* \\ Saad M. Nada* \\ Yasameen Ali Hadi*
}

\author{
PhD (Molecular) \\ MSc (Biotechnology) \\ PhD (Genetic) \\ MSc (Biotechnology)
}

\section{Summary:}

Background: The human CD19 (Cluster Differentiation) antigen is a $95 \mathrm{kd}$ transmembrane glycoprotein belonging to the immunoglobulin superfamily. CD19 gene located on the short arm of chromosome 16p11.2 (P: petit). CD19 is a member of the Ig immunoglobulin superfamily expressed on the surface of B lymphocytes, and may play a pivotal role in B-cell differentiation and activation. Research suggests that mutations in a gene CD19 leads to a lack of expression of CD19 membrane and result in an antibody deficiency syndrome.

Fac Med Baghdad 2014 Vol.56, No.4 Received: Jan, 2014 Accepted Sept 2014

Objective: The aim of this work is to study the mutations in Exon 2 CD19gene in leukemia patients in Baghdad/Iraq.

Patients and Methods: This cross sectional study was performed in the National Center of Hematological Diseases/Al Mustanisyria University. Blood samples were collected from 50 leukemia patients including (25 acute lymphocyte leukemia ALL and 25 chronic lymphocyte leukemia CLL) and 50 samples of apparently healthy individuals. DNA was isolated and the CD19 gene was amplified by using specific primers for exon2 of this gene. The nucleotide sequences of CD19 gene was according to Macro gene company, USA. Analysis was done using BLAST program which is available online at (http:// www.ncbi.nlm.nih.gov) and BioEdit program.

Results: The DNA sequencing results of flank sense of CD19 gene from healthy individual was found to be compatible 100\% with wild type of Homo sapiens from the Gene Bank, while 99\% compatibility was found for that gene of all ALL and CLL patients with wild type of gene. The difference was attributed to insertion of 1900 C nucleotide in position +48 of exon 2 of CD19 gene resulted in the replacement of a serine (TCC) residue into isoluseine (ATC), and deletion $1904 \mathrm{C}$ in position +49 of exon 2 . This mutation resulted in change of codon from GCA to GCC but there was no changes in the amino acid (Alanine to Alanine). The second mutation (Deletion nucleotide) amended the first mutation effect (Insertion nucleotide) and did not lead to a change of all the amino acid sequence (framshift). The results showed that the incidence of insertion and deletion mutation at position +48 and +49 in exon 2 of CD19 gene and leukemia was highly significant $(\mathrm{X} 2=15.75, \mathrm{P}<0.01)$.

Conclusion: This study suggests that the ploymrphism in exon 2 of the CD19 gene is strongly associated with leukemia patient of Baghdad population.

Keywords: Framshift mutation, acute lymphocyte leukemia ALL, chronic lymphocyte leukemia CLL, CD Cluster Differentiation.

Introduction:

The human CD19 antigen is a $95 \mathrm{kd}$ transmembrane glycoprotein belonging to the immunoglobulin superfamily (1 and 2). It is encoded by the 7.41 kilobite CD19 gene located on the short arm of chromosome 16, 16p11.2 (3 and 4). The gene contains 15 exons and codes for the CD19 molecule with 556 amino acids. Structurally, the gene contains an unusually short 5'-untranslated region. The proximal CD19 promoter lacks a TATA box, and its major start sites are found within 50 bp of the initiation codon (5). CD19 is classified as a type I transmembrane protein, with a single transmembrane domain, a cytoplasmic C-terminus, and extracellular N-terminus. During B-cell differentiation in the bone marrow, the surface

\footnotetext{
* Biotechnology Research Center, Al-Nahrain University, E-mail:najwaun@yahoo.com
}

molecule CD19 appears early and remains on the B cell until it differentiates into a plasma cell. Four proteins are recognized on the surface of mature B cells CD19, CD21, CD81, and CD225 form the CD19 complex, which signal in conjunction with the B-cell antigen receptor, there by decreasing the threshold for receptor-dependent signaling (6 and 7). CD19 is a biomarker for normal and neoplastic B cells, as well as follicular dendritic cells. Though it is not known if CD19 contributes directly to B cell carcinogenesis, its expression is highly conserved on most B cell tumors (8). CD19 is a type I membrane protein of the immunoglobulin superfamily, which is expressed in nearly all stages of B-cell development, and also on the majority of chronic B-lymphocytic leukemia (CLL), non-Hodgkin lymphoma and acute B-lymphoblastic leukemia (ALL) cells. The antigen is 
rarely lost during malignant transformation and is not shed from the cell surface. These properties have established CD19 as an attractive target antigen for new antibody-based therapeutics for B-lymphoid malignancies (9). The types of leukemia also can be grouped based on the type of white blood cell that is affected. Leukemia can start in lymphoid cells or myeloid cells. Chronic lymphocytic leukemia (CLL): affects lymphoid cells and usually grows slowly. Most often, people diagnosed with the disease are over age 55. It almost never affects children (10). Acute lymphocytic leukemia (ALL): affects lymphoid cells and grows quickly. ALL is the most common type of leukemia in young children; It also affects adults (11). CD19 is a member of the Ig superfamily expressed on the surface of B lymphocytes, and may play a pivotal role in B-cell differentiation and activation (12). The majority of B cell malignancies express CD19 at normal to high levels (80\% of ALL, $88 \%$ of B-cell lymphomas and $100 \%$ of B cell leukemias) (13 and 14), the morphology of cells and expression status of specific surface markers, such as CD5, CD19, CD20, CD38 and CD45, have long been considered as the essential indicators for the diagnosis and prognosis of B-cell chronic lymphocytic leukemia (B-CLL) (15). The aim of this work was to study the mutations in exon 2 of CD19 gene in Leukemia patients in Baghdad/ Iraq.

\section{Materials and Methods:}

Samples and DNA extraction: Whole blood samples were obtained from fifty Iraqi patients affected by Leukemia (25 ALL and 25 CLL, age ranged from 4 to 25 years) and also obtained from 50 healthy individuals used as a control group. Patients were admitted to the National Center of Haematology Diseases/ Al Mustanisyria University. The disease was clinically diagnosed by the consultant medical staff at the centre.In total, $4 \mathrm{ml}$ of whole blood was collected into an EDTA- tube; the samples were stored at $-20^{\circ} \mathrm{C}$ until further processing. DNA was extracted from the samples by DNA extraction kit (Wizard ${ }^{\circledR}$ Genomic DNA Purification Kit, Promega, Madison, WI, USA) according to the manufacturer's protocol.

Detection of Gene CD19 by Using PCR: Detection of CD19 gene was conducted by using primers for amplification of for exon 2 CD19 gene. A fragment 865 bp of CD19 was amplified using a forward primer (CD19F: 5'GGAAGGTATGTCCAAAGGGCA-3') and a reverse primer (CD19R:5'-CCACCTAGGTCCGAAACAT-3') (Primers set were supplied by alpha DNA Company, Canada). The PCR amplification was performed in a total volume of $25 \mu \mathrm{l}$ containing $1.5 \mu \mathrm{l}$ DNA, $12.5 \mu \mathrm{l}$ Go Taq green master mix $2 \mathrm{X}$ (Promega corporation, USA), $1 \mu \mathrm{l}$ of each primer (10 pmol) then the volume was completed to $25 \mu \mathrm{l}$ with nucleases free water. The thermal cycling conditions were done as follows: Denaturation at $94{ }^{\circ} \mathrm{C}$ for $5 \mathrm{~min}$, followed by 35 cycles of $94{ }^{\circ} \mathrm{C}$ for $35 \mathrm{~s}, 62^{\circ} \mathrm{C}$ for $1 \mathrm{~min}$ and $72{ }^{\circ} \mathrm{C}$ for $1 \mathrm{~min}$ with final incubation at $72{ }^{\circ} \mathrm{C}$ for $7 \mathrm{~min}$ using a thermal cycler (Gene Amp, PCR system 9700; Applied Biosystem). The PCR products were separated by 1.5\% agarose gel electrophoresis and visualized by exposure to ultraviolet light (302nm) after ethidium bromide staining.

Sequencing and Sequence Alignment: Sequencing of exon 2 of CD19 gene from 50 leukemia patients including (25 acute lymphocyte leukemiaALL and 25 chronic lymphocyte leukemia CLL) and 50 samples of apparently healthy individuals was performed by AB13730XL, Applied Biosystem, Macro gen company, USA. Homology search was conducted using Basic Local Alignment Search Tool (BLAST) program which is available at the National Center Biotechnology Information (NCBI) online at (http://www.ncbi.nlm.nih.gov) and BioEdit program. The results were compared with data obtained from Gene Bank published ExPASY program which is available at the NCBI online.

Statistical analysis: Medical statistics of this study was conducted via computer based statistical program, $\mathrm{X}^{2}$ test was applied for windows computer package. 'The statistical analysis tests were considered significant when $P$ value $<0.01$, compare between control and patients group in \% of mutation, Chi-square $-\mathrm{X}^{2}$ test was used to compare the significance between percentage shown as table 1 .

\section{Results:}

CD19 gene was successfully amplified using specific PCR primers for exon 2. Figure (1) showed PCR amplification of exon 2 of the CD19 where a specific product at 862 bp was observed. Sequencing of this gene was performed to detect variant insertion $\mathrm{C}$ at position +48 and deletion $\mathrm{C}$ at position +49 which related to development of disease. Sequences alignment using BLAST and BioEdit showed that the $100 \%$ similarity of healthy sample, score 736 and expect 0.0 with wild type of the CD19 gene of Homo sapiens from the Gene Bank (Figure 2). The CD19 gene from 50 leukemia patients (25 sample of ALL and 25 sample of CLL) shows 99\% compatibility, score 783 and expect 0.0 with the wild type sequences of CD19 gene from Gene Bank as shown in figure (3). There is one insertion $\mathrm{C}$ at position +1900 , that caused a serine (TCC) change to isoluseine (ATC) substitution in codon 48, there was a highly significant association between leukemia and incidence of insertion of + $48 \mathrm{C}$ position in exon 2 of CD19 gene $\left(\mathrm{X}^{2}=15.75, \mathrm{P}<0.01\right)$, and deletion $\mathrm{C}$ at position 1904 of exon 2, resulted in a change of the codon from (GCA) to ( GCC), but did not change the amino acid (Alanine to Alanine) in codon number 49. Table (1) shows the type of mutation and the effect of these mutations, the second mutation (Deletion nucleotide) amended influence the first mutation (Insertion nucleotide) and did not lead to a change all amino acid (framshift). Translation of exon 2 CD19 gene of all groups (healthy and patient) to a protein sequence, is shown in Figure (4), the results were compared with data obtained from Gene Bank published ExPASY program which is available at the NCBI online at www.ncbi.nlm.nih.gov. 


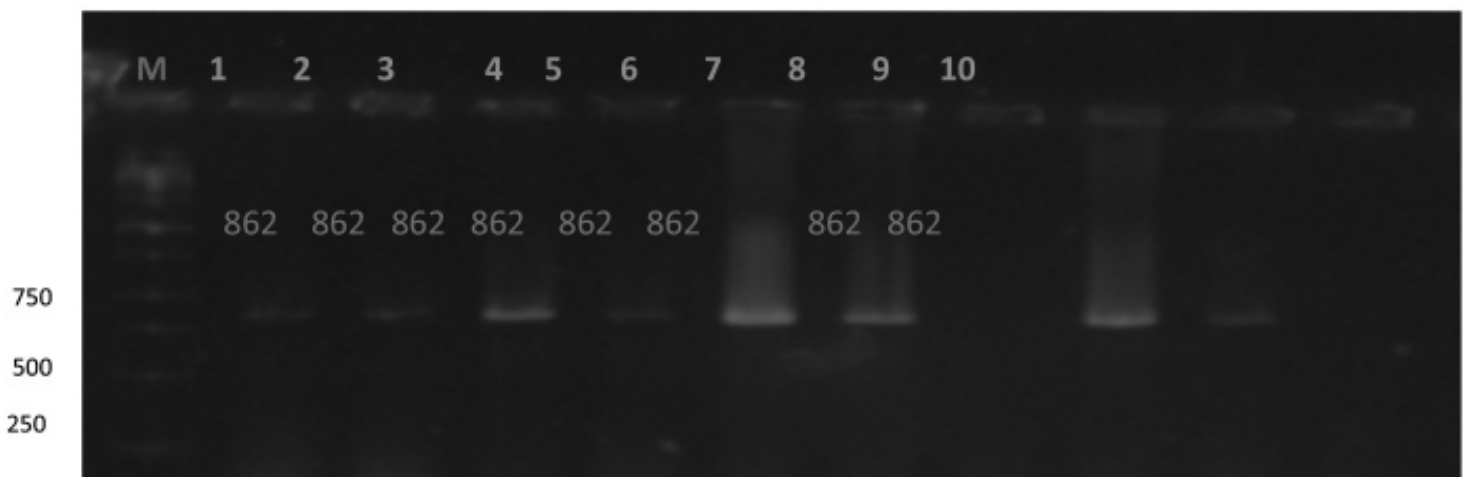

Figure (1): Agarose gel electrophoresis for amplified CD19 gene of lymphocyte belonging to healthy, ALL, and CLL patients was done. Bands were fractionated by electrophoresis on a $1.5 \%$ agarose gel $(2 \mathrm{~h} ., 5 \mathrm{~V} / \mathrm{cm}, 1 \mathrm{X}$ Tris-acetic buffer) and visualized under U.V. light after staining with ethidium bromide staining. Lane M:250bp ladder. Lane:1,2,3 (Healthy), Lane:4,5,6.(ALL), Lane: 8,9.(CLL).

$\begin{array}{cllll}\text { Frame Strand } & \text { Gaps } & \text { Identities } & \text { Expect } & \text { Score } \\ \text { Plus/Plus } & \mathbf{0 / 7 3 6 ( 0 \% )} & 736 / 736(100 \%) & 0.0() & 1360 \text { bits (736) }\end{array}$

Query

TTAAACCСTTCTTAAAACTCAGCCTGGGGCTGCCAGGCCTGGGAATCCACATGAGGCCCC 354 |||||||||||||||||||||||||||||||||||||||||||||||||||||||||||||

Sbjct

TTAAACCCTTCTTAAAACTCAGCCTGGGGCTGCCAGGCCTGGGAATCCACATGAGGCCCC 5551

Query

TGGCCATCTGGCTTTTCATCTTCAACGTCTCTCAACAGATGGGGGGCTTCTACCTGTGCC 414 ||||||||||||||||||||||||||||||||||||||||||||||||||||||||||||

Sbjct

TGGCCATCTGGCTTTTCATCTTCAACGTCTCTCAACAGATGGGGGGCTTCTACCTGTGCC 5611

Query

AGCCGGGGCCCCCCTCTGAGAAGGCCTGGCAGCCTGGCTGGACAGTCAATGTGGAGGGCA 474

Sbjct

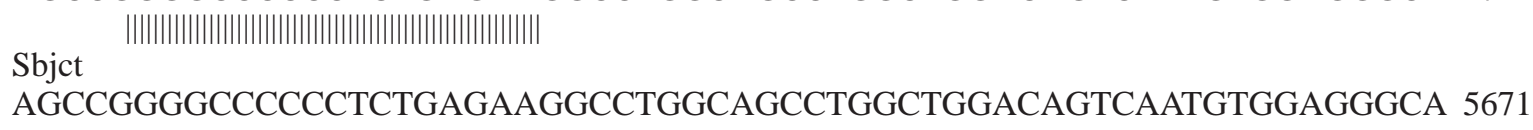
|||||||||||||||||||||||||||||||||||||||||||||||||||||||||||||

AGCCGGGGCCCCCCTCTGAGAAGGCCTGGCAGCCTGGCTGGACAGTCAATGTGGAGGGCA 5671

Figure. (2): Sequencing of sense flanking the partial CD19 gene for healthy as compared with standard CD19 obtained from Gene Bank. Query represent of sample; Sbject represent of database of National Center Biotechnology Information (NCBI). The bit Score: Statistical measure of the moral similarity and the higher value indicates that the high degree of similarity, and if dropped from the class of 50 points, the sense that there is no similarity mention. Expectation value: Give an estimate of the number of times the expected to get the same similarity coincidental and the lower the value of $E$ whenever this indicates that the degree of similarity high between sequences which gives greater confidence that this relay views already follow under study, as the value of a very close to zero means that these sequences are identical.

$\begin{array}{cccccc}\text { Frame } & \text { Strand } & \text { Gaps } & \text { Identities } & \text { Expect } & \text { Score } \\ & \text { Plus/Plus } & 2 / 790(0 \%) & 788 / 790(99 \%) & 0.0() & 1447 \text { bits(783) }\end{array}$

Query

TAAACCCTTCTTAAAACTCAGCCTGGGGCTGCCAGGCCTGGGAATCCACATGAGGCCCCT 360

Sbjct

TAAACCCTTCTTAAAACTCAGCCTGGGGCTGCCAGGCCTGGGAATCCACATGAGGCCCCT 1896

Query

GGCCATC-TGGCTTTTCATCTTCAACGTCTCTCAACAGATGGGGGGCTTCTACCTGTGCC 419

Sbjct

GGC-ATCCTGGCTTTTCATCTTCAACGTCTCTCAACAGATGGGGGGCTTCTACCTGTGCC 1955

Query

AGCCGGGGCCCCCCTCTGAGAAGGCCTGGCAGCCTGGCTGGACAGTCAATGTGGAGGGCA 479

Sbjct

AGCCGGGGCCCCCCTCTGAGAAGGCCTGGCAGCCTGGCTGGACAGTCAATGTGGAGGGCA 2015 
Figure. (3): Sequencing of sense flanking the C19 gene for Leukemia (ALL and CLL) as compared with standard CD19 obtained from Gene Bank, (25 ALL; 25 CLL patients). Query represent of sample; Sbject represent of database of National Center Biotechnology Information (NCBI). The bit Score: Statistical measure of the moral similarity and the higher value indicates that the high degree of similarity, and if dropped from the class of $\mathbf{5 0}$ points, the sense that there is no similarity mention. Expectation value: Give an estimate of the number of times the expected to get the same similarity coincidental and the lower the value of $E$ whenever this indicates that the degree of similarity high between sequences which gives greater confidence that this relay views already follow under study, as the value of a very close to zero means that these sequences are identical.

Table (1): Types of mutations detected in partial exon 2 CD19 gene of Leukemia patients (25 sample of ALL and 25 sample of CLL).

\begin{tabular}{cccccc}
\hline Type of substitution & Predicted effect & Amino acid change & No. of sample & Nucleotide change & Location of gene bank \\
\hline Insertion 1900 & Missense & Serine (S) / Isoleusine (I) & 50 & ATC>TCC & C/ 48+ \\
\hline Deletion 1904 & Silent & Alanine (A) / Alanine (A) & 50 & GCC>GCA & C/ 49+ \\
\hline
\end{tabular}

Query 3 AVLQCLKGTSDGPTQQLTWSRESPLKPFLKLSLGLPGLGIHMETRPLASWLFIFN

Sbjct 3 AVLQCLKGTSDGPTQQLTWSRESPLKPFLKLSLGLPGLGIHMETRPLAIWLFIFN 62

Query 63 VSQQMETGGFYLCQPGPPSEKAWQPGWTVNVEG 95

Sbjct 63 VSQQMETGGFYLCQPGPPSEKAWQPGWTVNVEG 95

Figure (4): Amino acid sequence of the translated exon 2 in CD19 both in healthy individuals and patient group, the character in group is the site of mutation with change from Seine to Isoleucine. Query represent of sample; Sbject represent of database of National Center Biotechnology Information (NCBI).

\section{Discussion:}

Presence of mutation within exon 2 in CD19 gene lead to change the amino acid serine to isoluseine, and lead to a change in conformation of protein and thus a change in gene expression and its less efficient, and this is identical to other research, patients with mutations in the CD19 (MIM 107265) gene have reduced immunoglobulin (Ig) serum levels, reduced memory B cell numbers and impaired antibody responses to vaccinations (16 and 17). Hypogammaglobulinemic patients from two unrelated families were shown to have defective CD19, resulting from mutations in the CD19 gene, describe a new case of CD19 deficiency with two novel mutations in the CD19 gene (16). Van Zelm et al., and Kanegane, et al., (16 and 17) described a CD19 deficient patient, who was compound heterozygous for two novel mutations, these mutations lead to loss of CD19 membrane expression, and result in an antibody deficiency syndrome, characterized by recurrent (mainly) bacterial infections. The mutation in the splice acceptor site of exon 6 (IVS5-1G4T) results in skipping of exon 6, placing exon 7 out-of frame after exon 5, which leads to a premature stop codon at the intracellular amino acid. In line with this, the patient's B cells completely lack membrane CD19 expression. Furthermore, the lack of all intracellular domains responsible for signal transduction makes any expressed protein non functional (18). Zelm, et al., (19) showed a 156G.C mutation resulted in the replacement of a tryptophan residue into a cysteine (W52C), the affected tryptophan is located in domain 1 of CD19 and corresponds to nucleotide mutation 123G.C and amino acid change W41.C in exon 2 of CD19 of antibody deficiency. (8), refere to not known if CD19 contributes directly to B-cell carcinogenesis, its expression is highly conserved on most B-cell tumors. CD19 expression is observed in normal plasma cells, malignant plasma (myeloma) cells isolated from multiple myeloma patients have been shown to lack CD19 expression, while isolates from premyeloma patients show a mix of both CD-19 and CD+19 plasma cells (20). CD19 levels can potentially be useful as a diagnostic tool in distinguishing certain lymphoma subtype, follicular lymphoma, has lower CD19 level more frequently than any other lymphoma subtypes, low CD19 is also more common in CD10 positive than in CD10 negative diffuse large B cell lymphoma (21). The present study showed that there was significant correlation between leukemia and incidence of insertion $1900 \mathrm{C}$ nucleotide in position +48 of exon 2 of CD19 gene, despite the limited size of the sample, the results together with population studies show an association of mutation in CD19 with leukemia in Iraqi population.

\section{Author contributions:}

Study conception: Najwa Sh. Ahmed, Saad M. Nada, Zeina Saif Al-Dein Mohammed, Yasameen Ali Hadi,

Study design: Najwa Sh. Ahmed, Saad M. Nada, Zeina Saif Al-Dein Mohammed, 
Acquisition of data analysis: Najwa Sh. Ahmed, Saad M. Nada

Interpretation of data: Najwa Sh. Ahmed, Saad M. Nada, Zeina Saif Al-Dein Mohammed, Drafting of manuscript: Najwa Sh. Ahmed, Saad M. Nada, Yasameen Ali Hadi,

Critical revision: Najwa Sh. Ahmed,

\section{Reference}

1- Carter RH, and Barrington RA: Signaling by the CD19/ CD21 complex on B cells. Curr Dir Autoimmun 2004, 7:432.

2- Thierry-Mieg D, and Thierry-Mieg J: AceView: a comprehensive cDNA-supported gene and transcripts annotation. Genome Biol 2006, 7.(Suppl 1:S12):11-14.

3- Zhou LJ, Ord DC, Omori SA, and Tedder TF: Structure of the genes encoding the CD19 antigen of human and mouse B lymphocytes. Immunogenetics 1992, 35(2):102-111.

4- Haas KM, and Tedder TF: Role of the CD19 and CD21/35 receptor complex in innate immunity, host defense and autoimmunity. AdvExp Med Biol 2005, 560:125-139.

5- Kehrl JH, Riva A, Wilson GL, and Thevenin C: Molecular mechanisms regulating $\mathrm{CD} 19, \mathrm{CD} 20$ and $\mathrm{CD} 22$ gene expression. Immunol Today 1994, 15(9):432-436.

6- Carter RH, and Fearon DT. CD19: lowering the threshold for antigen receptor stimulation of B lymphocytes. Science 1992; 256:105-7.

7- Ishiura N, Nakashima H, Watanabe R, Kuwano Y, Adachi T, Takahashi Y, Tsubata T, Okochi H, Tamaki K, and Tedder TF. Differential phosphorylation of functional tyrosines in CD19 modulates B-lymphocyte activation. Eur J Immunol 2010, 40(4):1192-1204.

8-Poe JC, Minard-Colin V, Kountikov EI, Haas KM, and Tedder TF: A c-Myc and Surface cd19 signaling amplification loop promotes B cell lymphoma development and progression in mice. J Immunol, 2012, 189(5):2318-2325.

9- Stiegl M, JuliaB., Edwin K., Christian L., and Tanja M. Selective induction of apoptosis in leukemic B-lymphoid cells by a CD19-specific TRAIL fusion protein. Cancer Immunology, Immunotherapy, 2008, 57 (2): 233-246. (IVSL)

10- Porakishvili V, Kardava L, Jewell A, Yang K, Glennie M, Akbar A. and Lydyard P. Cytotoxic CD4 T cells in patients with B cell chronic lymphocytic leukemia kill via aperforin mediated pathway. Haematological, 2004, 89: 435-443.

11-Vardiman JW, Thiel J. and Arber DA. The 2008 revision of the world health organization (WHO) classification of myeloid neoplasms and acute leukemia, ration ate and important changes. Blood, 2009, 114:937-951.

12- Carter RH, and Fearon DT. CD19: lowering the threshold for antigen receptor stimulation of B lymphocytes. Science, 1992, 256: 105-107.

13- Tedder, TF, Inaoki M, Sato S: The CD19-CD21 complex regulates signal transduction thresholds governing humoral immunity and autoimmunity. Immunity 1997: 6(2): 107-118. 14- Cooper LI, Al-Kadhim Z, Diglusto D, Kalos M. Colcher $D$, Raubitschek A, Forman SJ. Jensen MC. Development and application of CD19-sepecific $T$ cells for adoptive immunotherapy of B cell malignancies. Blood cells Mol Dis. 2004, 33(1): 83-89.

15- Niu S, Chan R, Berini P, and Wang C. Morphology and expression status investigations of specific surface markers on B-cell chronic lymphocytic leukemia cells. Microscopy Research and Technique, 2013, 76 (11): 1147-1153. (IVSL)

16- Van Zelm MC, Reisli I, van der Burg M, Castano D, van Noesel CJM, and Van Tol MJD. An antibody-deficiency syndrome due to mutations in the CD19 gene. $N$ Engl J Med 2006, 354: 1901-1912.

17- Kanegane, H, Agematsu, K, Futatani, T, Sira, M, Suga, K, Sekiguchi, T, Van Zelm M. and T Miyawaki T. Novel mutations in a Japanese patient with CD19 deficiency. Genes and Immunity, 2007, 8, 663-670.

18-Van Zelm, MC, Smet, J, Adams, B, Mascart, F, Schandene, L, Janssen, F, Ferster, A, Kuo, CC, Levy, S, and Van Dongen, JJ. CD81 gene defect in humans disrupts CD19 complex formation and leads to antibody deficiency. J. Clin. Invest.2010, 120, 1265-1274.

19- Zelm, M, Smet, J, Burg, M, Ferster, A, Le, P, Schandene, L, Dongen, J, and Mascart, F. Antibody deficiency due to a missense mutation in CD19 demonstrates the importance of the conserved tryptophan 41 in immunoglobulin superfamily domain formation. Human Molecular Genetics, 2011, 20(9): 1854-1863.

20- Ishikawa H, Tsuyama N, Mahmoud MS, Fujii R, Abroun S, Liu S, Li FJ, Kawano MM. CD19 expression and growth inhibition of tumours in human multiple myeloma. Leuk lymphoma, 2002, 43(3): 613-616.

21- Yang W, Agrawal N, Patel J, Edinger A, Osei E, Thut D, Powers J, Meyerson H. Diminished expression of CD19 in B-cell lymphomas. Cytometry B clin. Cytom. 2005, 63(1): 2835. 